\title{
London Landscape - Book Review
}

24 Hours to Save the NHS: The Chief Executive's Account of Reform 2000-2006. Lord Nigel Crisp. Oxford University Press, 2011. ISBN: 978-0-19963995-3

The pseudo-urgency of the title made me approach this book with trepidation. Would it dishonour the many NHS workers who endured and sweated through new initiative after new initiative during the NHS Plan? Would it emphasise the glitz and gloss and political spin of reform, while downplaying the hard work, unintended consequences and uncertainties?

In fact, the 24 hours in the title refers only to a Tony Blair quotation from the eve of the 1997 election. The tale told here is as much about 'the sheer grind and the attention to detail that was needed to make large scale improvements ${ }^{11}$ as it is about the designs for development that 'excited and energised the planners and policy makers'. 1

According to the author:

'This book gives my personal account of running a massive national system during a period of reform. It shows what we set out to do and describes some of the successes and failures.

It was not straightforward and clear cut. Little actions ripple out, producing as many unintended consequences as intended ones. Paradoxes abound'. ${ }^{1}$

Like Nigel Crisp's other recent insightful book, ${ }^{2}$ this account is designed both for those within and outside of the NHS and the UK. It is nearly equal part story, memoir, analysis and putting into context. It is factual, personal, diagnostic, and instructive. It helps the reader to understand recent history, and provides enough situational analysis to allow thoughtful extrapolation of the principles and lessons to other circumstances. It provides suggestions for approaching the future.

The text is bookended by analyses of the local situation of the NHS and the global challenge - both of which require major modernisations while remaining true to core values. In between, the reader finds an overview and then an analysis of the NHS reforms of the era when Lord Crisp served as Chief Executive of the NHS and Permanent Secretary of the Department of Health. The analysis includes chapters on four areas of reform: service redesign, system reform, workforce restructuring, and knowledge, technology and science. The analysis then switches to the cross-cutting areas of finance and productivity, the personal role of the chief executive, and the central place of patients and society in efforts to advance health and health care. After a chapter summarising the key points, the author takes the lessons further to consider options for the future sustainability of the NHS, messages for the rest of the world from the recent NHS reform experience, and observations about steps and leaps that could improve health around the world. Four useful appendices provide additional context.

I found the story of the reforms, told from a true insider perspective, to be gripping. The narrative has both stories and statistics. Sir Austin Bradford Hill has been quoted that 'Health statistics represent people with the tears wiped off' ${ }^{3}$ Here the numbers and the narrative are so recent that both the tears and the sweat are still wet.

The memoir aspect of the book is not at all selfindulgent. The author was in charge of the implementation of a major reform. His position in the middle between the politicians, the NHS workers and the public was clearly exhilarating and at times frustrating. His belief in the mission and the importance of the NHS is unwaveringly apparent, even as others disagreed with his approach. He is unflinching in recounting failures as well as successes. I wondered how a leader in his position kept in touch, and was intrigued to learn that during his 20 years of working for the NHS in different leadership positions, he devoted most Fridays to visiting the diverse settings and people who make up the NHS. The description of engaging his driver as a key informant is endearing.

The analysis draws upon references to diverse thinkers and actors, and benefits from a frank and clear writing style that helps the reader make sense of this intense period in the life of the NHS. As someone who lived the reforms only vicariously through my friends and colleagues in the UK, Lord Crisp's account helped me to understand the rationale for the changes, some of the intended and unintended consequences, and how the pieces of the story fit together. I suspect that aspects of the story will both challenge and add narrative unity to the experience of those who lived through the reforms directly, whether that experience involved being an NHS patient, a health care worker, a policymaker, or some combination of the three. I still wonder about the potential longer-term unintended consequences that are not considered in the analysis, such as increasingly treating health care as a commodity rather than a relationship, but such matters move beyond what is knowable in the time frame of this analysis.

Putting into context a personal story, particularly one so publicly and intensely lived, is difficult. But the author's crisp inclusion of diverse historical, inter- 
national, numerical and narrative perspectives empowers readers to make their own analysis, and to draw the larger lessons from the author's interpretation in a way that allows the relevant principles to be discerned and applied in different circumstances.

The final chapters about transporting the lessons of this period of the NHS to the future or to other countries are appropriately portrayed in principles and possibilities rather than prescriptions. Because of the complex nature of healthcare and health, the author wisely avoids making stark predictions. But he does not shy away from sketching the important values and principles to guide action, suggesting both how to start, what the challenges will be, and what to pay attention to in order to develop a more helpful and broadly integrated health service and a healthier population. The suggested focus to 'enable people to live independently in a way they have reason to value, support the development of a healthy society, (and) contribute to the health of an interdependent world', resonates with articles in this issue of the London Journal of Primary Care. ${ }^{4}$ The path to a future that is more focused on promoting health than health care is full of challenge. This book gives us hope about the possibilities of what can be accomplished when people with solidarity, and individuals with vision, fortitude and resilience, work toward a common good.

\section{REFERENCES}

1 Crisp N. 24 Hours to Save the NHS: The Chief Executive's Account of Reform 2000-2006. Oxford: Oxford University Press, 2011.

2 Crisp N. Turning the World Upside Down - the search for global health in the 21st century. London: RSM Press, 2011.

3 Sir Austin Bradford Hill. Health statistics represent people with the tears wiped off. The Kerr White Health Care Collection. http://historical.hsl.virginia.edu/kerr/health stats.cfm.

4 Aungst H, Ruhe MC, Stange KC, et al. Boundary spanning and health: invitation to a learning community. London Journal of Primary Care 2011;4(2):

\section{ADDRESS FOR CORRESPONDENCE}

\section{Kurt C Stange}

Professor of Family Medicine, Epidemiology \& Biostatistics, Sociology and Oncology

Case Western Reserve University

11000 Cedar Ave, Suite 402

Cleveland

OH 44106

USA

Email: kcs@case.edu 